\title{
IDENTITAS DAN ORIENTASI NILAI KULTURAL MAHASISWA CALON GURU
}

\author{
Sudaryat Nurdin Akhmad ${ }^{1}$
}

\begin{abstract}
The research aims to learn profile of identity status and cultural value orientation of teacher prospective student. The research method that used is descriptive by qualitative approach. The research sample involves 80 students of education program at Universitas Pendidikan Indonesia that are chosen by using technique of multi stage cluster sampling. The collected data by questionnaire is analysized statisticaly. The research result shows that majority of teacher prospective students is on low cultural identity status. They are forecloser and diffusion. They who are in achievement status and moratorium, that is accused as high identity status, each of them is belonged by least of forth of students quantity. Four values that become strongest preferences for students are economic value, science value, social value and religious value. Some students that have achievement cultural identity status belong strong orientation on science value, then religious value and social value and economic value. Moratorium status put stronger orientation on economic value, social, aesthetic, and religious and the last is science. Foreclosure status put more orientation on economic value, social, and power. Besides, diffusion status put more orientation on economic value, power, social, aesthetic and religious.
\end{abstract}

Keywords: Cultural Identity, Competence, Education Prospective Teachers, Value Orientation, Identity Status.

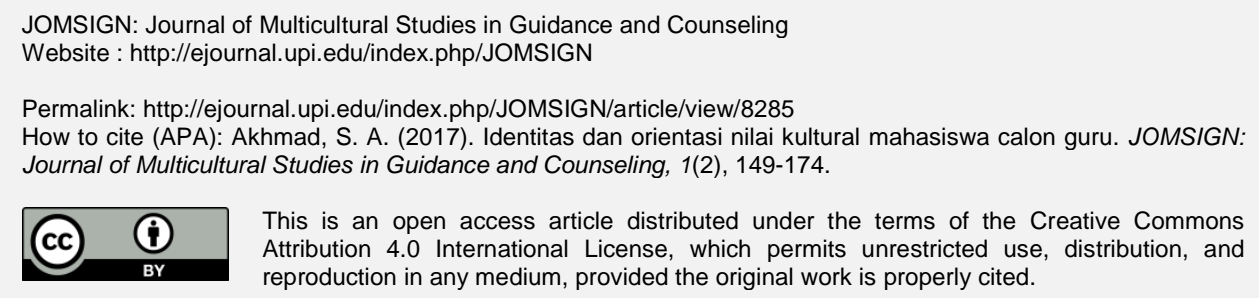

This is an open access article distributed under the terms of the Creative Commons Attribution 4.0 International License, which permits unrestricted use, distribution, and reproduction in any medium, provided the original work is properly cited.

\section{PENDAHULUAN}

Pendidikan di masa depan memerlukan diversifikasi layanan dan sensitivitas kultural karena semakin kompleksnya masalah serta beragamnya budaya peserta didik. Mahasiswa calon guru, yang dibina pada LPTK saat ini bukan untuk menjadi pendidik anak sekarang dan di sini, melainkan harus dipersiapkan untuk mampu menjadi pendidik anak masa depan yang mungkin situasi dan tuntutannya sangat berbeda dan jauh lebih berat dibandingkan

\footnotetext{
${ }^{1}$ Universitas Pendidikan Indonesia (UPI) Bandung, Indonesia; sunurakhmad@upi.edu.
} 
dengan kondisi sekarang. Masa depan merupakan sesuatu yang kompleks, sarat kompetisi, dan sulit diprakirakan (Kartadinata, 1998), namun memungkinkan untuk diantisipasi. Kondisi masa depan hanya mungkin dapat diantisipasi oleh guru yang selain kompeten secara profesioanal, juga harus memiliki competitive advantage dan memiliki daya adaptabilitas Ipteks yang tinggi melalui belajar secara berkelanjutan dalam fondasi Imtaq yang kokoh. Sehubungan itu, upaya mempersiapkan guru masa depan di Abad ke-21, tidak cukup hanya dengan membekali kecakapan profesional di atas standar minimal kompetensi lulusan, melainkan harus lebih jauh dari itu. Pendidikan calon guru harus sampai menyentuh pada apa yang disebut oleh Kartadinana (2015) sebagai misi. Misi ini penting karena dalam perspektif pedagogis, guru harus mampu membawa peserta didik dari apa adanya kepada kondisi bagaimana seharusnya. Misi itu hanya dapat dicapai oleh guru yang memiliki identitas atau jati diri. Keterkaitan antara kompetensi, jati diri, dan misi, diilustrasikan oleh Kartadinata (2015) dalam gambar berikut.

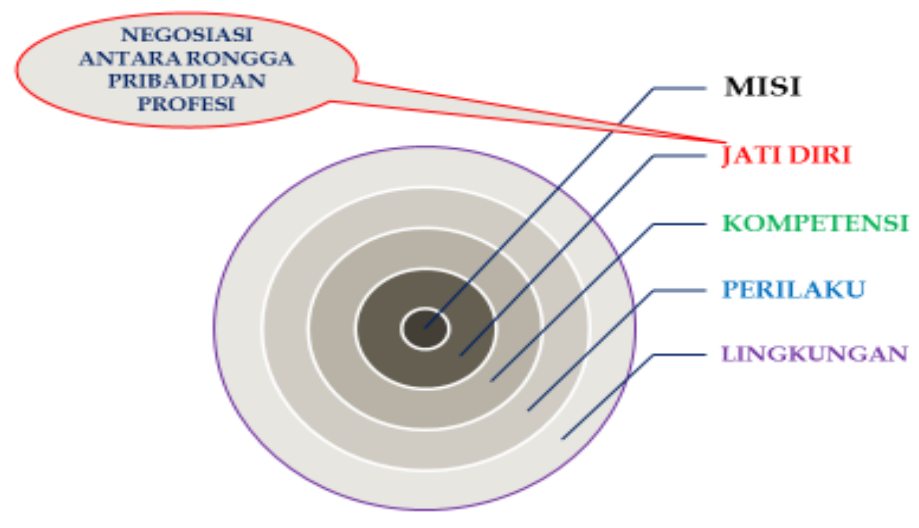

Gambar 1. Reorientasi Pendidikan Guru dari Kompetensi ke Jati Diri dan Misi

Diskursus pendidikan guru yang selama ini ramai diperbincangkan, baru terbatas pada dimensi kompetensi, belum mempersoalkan bagaimana pembentukan identitas apalagi strategi membangun guru yang memiliki misi. Padahal tantangan dunia pekerjaan guru di Abad ke-21 menuntut reorientasi paradigma belajar. Mahasiswa calon guru tidak cukup hanya menguasai kompetensi yang menjadi tuntutan program studi, melainkan harus belajar untuk mempersiapkan diri secara matang dalam penentuan perikehidupan dan 
pilihan menjadi guru sebagai work of life dan sumber kepuasan pribadi di sepanjang kehidupannya. Pekerjaan sebagai guru tidak hanya disandang sebatas sebagai karir, melainkan lebih jauh dari itu yakni, sebagaimana disebut para ahli, sebagai suatu vokasional (Cullen, 2013; Leong, 2008). Penentuan pilihan vokasi tersebut mereka lakakukan setelah melalui serangkaian upaya eksplorasi informasi yang luas dan dalam kemudian dilanjutkan dengan komitmen yang kuat terhadap pilihan tersebut. Dalam teori Marcia, orang-orang seperti itu dikategorikan memiliki status identitas achievement (Marcia, et al., 1993).

Bagaimana mendidik guru yang selain memiliki kompetensi juga memiliki identitas yang kokoh untuk mencapai misi membawa peserta didik peserta didik dari kondisi apa adanya kepada kondisi bagaimana seharusnya di masa depan, diperlukan perspektif baru dalam paradigma pedagogik pendidikan guru. Bagaimana arah baru pendidikan untuk membentuk guru Abad ke-21 dan bagaimana identitas kultural calon guru itu dibentuk melalui proses pendidikan prajabatan, merupakan topik utama yang menarik untuk dikaji secara mendalam.

Di Abad ke-21, pembelajaran sudah merupakan suatu keharusan untuk memperoleh kelangsungan hidup yang bermakna. Geissier (dalam Surya, 2003) menyatakan bahwa, "learning become ciricen's first duty. Stop learning and you stop living". Lebih lanjut dungkapkan oleh Geissier bahwa di Mellennium ketiga ini kita dituntut untuk melakukan learning offensive. Ada empat alasan perlunya learning offensive, yaitu: (1) pola-pola individuasi dalam era postmodern, yaitu adanya dorongan untuk self-fulfilment yang berlangsung secara simultan dengan keharusan untuk mencapainya; (2) makin meningkatnya perilaku reflektif dalam kehidupan, yaitu proses perilaku osilatif atau pemantulan antara satu keadaan dengan keadaan lainnya dalam pembuatan keputusan, seperti antara berpikir dan bertindak, antara apa yang diamati dengan apa yang dilakukan; (3) tantangan globalisasi dan internasionalisasi, yang menuntut wawasan yang tanpa batas; dan (4) adanya koreksi terhadap struktur waktu masyarakat yang disebut dengan fleksibilisasi yaitu kecenderungan adanya fleksibilitas pola waktu dan tempat dalam berbagai aspek kehidupan

Untuk mampu mewujudkan learning offensive, menurut Geissier diperlukan empat kompetensi, yaitu: (1) plurality competence, yakni kecakapan untuk mengidentifikasi aspek produktif dari adanya keragaman dan toleransi serta menggunaannya secara efektif; (2) socio-communicative competence, yakni kecakapan untuk berinisiatif, mengembangkan, mendukung, mengelola, dan 
menyimpulkan secara tepat proses-proses sosial; (3) transition competence, yaitu kecakapan untuk beradaptasi dengan proses transisi dalam kehidupan; dan (4) equilibrium competence, yakni kecakapan dalam menjaga keseimbangan dalam kondisi ketidakpastian. Sensitivitas dan identitas budaya tampaknya merupakan salah satu aspek plurality competence sebagaimana digagas oleh Geissier.

Untuk memahami makna identitas dan identitas budaya, antara lain dapat ditelusuri melalui teori perkembangan psikososial dari Erikson (1968). Erikson membuat rangkaian teori perkembangan ego untuk mengetahui interaksi antara faktor psikologis, sosial, sejarah dan perkembangan dalam pembentukan kepribadian. Erikson memberikan pengaruh yang sangat besar dalam konsep perkembangan kepribadian remaja. Secara khusus, teori identitas Erikson (1968), yaitu krisis pada masa remaja, memberkan kerangka teoritis untuk mengukur pembentukan identitas.

Pada awalnya, Erikson tertarik dengan kesulitan yang dialami oleh beberapa Veteran Perang Dunia II yang kembali ke masyarakat. Erikson tertarik dengan masalah yang berkaitan dengan Acute Identity Diffusion. Setelah beberapa waktu melakukan penelitian klinis Erikson mempercayai bahwa kesulitan patologis yang dialami para veteran perang dalam meninggalkan satu peran (yakni sebagai tentara) dan memasuki peran lainnya (yakni sebagai warga sipil), secara psikologis, sama dengan yang dialami remaja saat mereka meninggalkan masa kanak-kanak dan berpindah ke masa transisi remaja dan menuju masa dewasa. Dari kerangka penelitian Erikson ini menghasilkan psikologi pembentukan identitas remaja (Adam, 1998).

Selanjutnya, apa yang dimaksud identitas oleh Erikson. Berdasarkan pemikiran psikoanalisis dengan menekankan pada perkembangan ego, Erikson merumuskan beberapa definisi identitas. Berdasarkan pada konsep bahwa ego mengorganisasikan kepribadian yang koheren dengan kesamaan dan perasaan yang berkelanjutan oleh orang lain, Erikson (1968, p. 50) menyatakan bahwa:

Ego identity then, in its subjective aspect, is the awareness of the fact that there is a self-sameness and continuity to the ego's synthesizing methods, the style of one's individuality, and that this style coincides with the sameness and continuity of one's meaning for significant others in the immediate community.

Dalam tulisan sebelumnya, Erikson (1956) menyatakan bahwa istilah identitas memiliki dua arti, yaitu kesamaan yang persisten dengan seseorang (kesamaan diri) dan kesamaan beberapa karakter penting dengan orang lain. Melalui 
tulisannya, Erikson menunjukan bahwa kesamaan diri dan kontinuitasnya ditunjukkan melalui perasaan sadar akan identitas individu, ketidaksadaran yang digunakan untuk melanjutkan karakter personal, proses kontinuitas sintesis ego dan solidaritas dalam diri dengan kelompok identitas ideal dan sosial.

Erikson (1968, p. 208) mendefinisikan identitas dalam pengertian yang beragam, "at one time seemed to refer to a conscious sense of individual uniqueness, at another to an unconscious striving for a continuity of experience, and a third, as a solidarty with a group's ideal". Namun pada bagian lain dikatakan bahwa "ego identity, then, is the result of the synthesizing function on one of the ego's frontier, namely, that environment which is social reality as transmitted to the child during successive childhood crises" (Erikson, 1968, p. 211).

Selain kesulitan dalam memahami definisi Erikson itu, Josselson (dalam Archer, 1994, p. 16) memberi komentar, "Erikson's legacy of the concept of identity was heuristic and connotative rather than operational and concrete". Miller (1993, p. 171) juga menilai, "Erikson's theory is a loose connection of abservations, emprical generalizations, and abstract theoritical claims". Dalam kondisi kebingungan itu, Marcia kemudian menyodorkan sebuah definisi kombinasi antara Erikson dan Marcia (Marcia, 1993, p. 3) bahwa "Identity formation involves a synthesis of childhood skills, belief, and identifications into a more or less coherent, unique whole that provides the young adult with both a sense of continuity with the past and a direction for the future". Sebagai suatu inner organizations, Marcia (1993, p. 3) menambahkan bahwa "identity comprises both precedural sytles and elements of content. More simply, identity, as a structure, refers to how experience is handler as well to what experiences are considered important". Akhirnya, Dreyer (dalam Archer, 1994, p. 123) mendudukkan persoalan ini sebagai berikut.

Although the psychological theory about identity formation can be traced to the work Erikson $(1950,1959,1982)$, the most recent advances in the field have resulted from Marcia's $(1966,1980)$ description of identity as a set of statuses that are defined by the extent to which an individual has explored options for his or her life and has shown evidence of having made a commitment to an occupation and an ideology. Successful identity achievers in this framework are high in both exploration and commitment. Given this definition, identity 
formation in adolescent can be encouraged and promoted by surrounding them with educational environments that stimulate exploration and commitment Marcia (1980, 1993) mengkonseptualisasikan pembentukan identitas secara lebih operasional dan konkrit berdasarkan inti gagasan psikososial Erikson menegaskan bahwa individu secara ideal akan membuat komitmen setelah melalui eksplorasi terhadap berbagai kemungkinan atau alternatif yang ada. Komitmen adalah titik akhir dari proses eksplorasi (Archer, 1994). Makna eksplorasi dan komitmen identitas dapat dipahami dalam uraian berikut.

Definisi eksplorasi identitas antara lain dapat dipahami melalui tulisan para ahli (Waterman dalam Marcia, 1993; (Marcia dalam Lapsley, 1990). Dari tulisan para ahli itu, dapat dijelaskan bahwa eksplorati identitas merupakan suatu periode dimana remaja sedang berjuang atau secara aktif bertanya (menjajaki, mengidentifikasi, mencari tahu, menggali, menyelidiki) tentang berbagai alternatif guna pencapaian suatu keputusan mengenai tujuan-tujuan, nilai-nilai, dan keyakinan. Sebagai masa krisis periode ini juga dapat berarti suatu masa pengujian terhadap pilihan-pilihan yang pernah ada sebelumnya, sebagaimana dikatakan Archer (dalam Marcia, 1993, p. 178) bahwa, "exploration (crisis) pertains to the examination of alternatives with the intention of establishing a firm commitment in the near future”. Marcia (dalam Lapsley, 1990: 219) memperkuat pendapat diatas dengan menegaskan bahwa "eksploration, as a defining variable in identity status determination, refers to cognitive and behavioral investigation and testing of alternative occupations, beliefs, and styles of selfpresentation and relationships".

Menurut Marcia et al (1993, pp. 206-211) proses eksplorasi dalam rangka pembentukan status identitas pada remaja akhir, ditandai oleh sejauhmanakah remaja melakukan penjajagan terhadap berbagai hal yang berkenaan dengan domain identitas sebagaimana direfleksikan oleh keluasan dan kedalaman aspek: knowledgeability, activity directed toward gathering information, considering alternative potential identity elements, and desire to make an early decision.

Sementara itu, untuk memahami makna komitmen identitas antara lain dapat merujuk pada tulisan sejumlah ahli (Waterman dalam Marcia, 1993; Marcia dalam Miller, 1993; Marcia dalam Lapsley, 1990; Marcia, 1993; Archer, 1994). Mereka memandang bahwa komitmen sinomin dengan kesetiaan, keteguhan pendirian, sungguh-sungguh melakukan suatu pilihan yang telah diputuskan dengan mantap di antara berbagai kemungkinan, dan kesetiaan pada arah yang 
dipilih dalam menghadapi alternatif yang membingungkan dan lebih menarik. Terhadap pilihan yang mantap, remaja dituntut mengeksperesikan tindakan yang ditunjukkan melalui kesungguhan dalam menerapkan pilihan tersebut. Remaja yang memiliki komitmen berketetapan hari untuk mempertahankan pilihannya, tegar memper-tahankan prinsip, bersikap kukuh dalam pendirian, dan tidak bergeming terhadap godaan-godaan.

Indikasi ada-tidaknya komitmen identitas pada remaja dapat ditunjukkan dengan kriteria: knowledgeability, activity directed toward implementing the chosen identity element, emotional tone, identification with significant others, projecting one's personal future, and resistance to being swayed (Marcia,1993: 206-211).

Pencapaian status identitas idealnya ditempuh remaja dengan cara penetapan komitmen setelah melalui eksplorasi terhadap berbagai alternatif yang ada. Komitmen merupakan kulminasi dari proses eksplorasi (Marcia dalam Archer, 1994: 17). Dalam kenyataannya, karena beragam alasan, resolusi krisis identitas seperti itu tidak selalu dapat ditempuh dengan mudah oleh setiap remaja. Sehubungan dengan hal itu, ada empat gaya yang mungkin ditampilkan remaja dalam melakukan resolusi masalah identitas berdasarkan pada ada-tiadanya eksplorasi dan komitmen, yaitu Identity Achievement, Moratorium, Identity Foreclosure, dan Identity Diffusion. Keempat gaya resolusi masalah identitas itu oleh Marcia disebut status identitas (Adelson, 1980, p. 161). Status identitas tersebut menurut Waterman dapat dimaknai bukan sekedar sebagai suatu kategori melainkan dapat juga menunjukkan tingkatan perkembangan (Marcia et al, 1993, p. 174).

Mengingat bahwa dalam praktek pengukuran eksplorasi dan komitmen itu kecil memungkinan ditemukan individu yang sama sekali tidak memiliki skor aksplorasi atau sama sekali tidak memiliki skor komitmen, maka Orlofsky et al, (1977) sebagaimana dikutip Matteson dalam Marcia et al (1993, p. 106) mengusulkan strategi baru untuk menentukan status identitas. Status identitas tidak mereka tentukan berdasarkan ada-tiadanya eksplorasi dan komitmen melainkan memperhalusnya dengan menyebut tinggi-rendahnya eksplorasi dan komitmen. Cara ini telah diaplikasikan dalam penelitian oleh Spence \& Helmreich (1978), Tesch (1984), dan Grotevant et al (1982) dengan hasil yang gemilang.

Status identitas Achievement adalah remaja yang telah melalui masa eksplorasi intens dan telah membuat komitmen yang definitif tentang isu-isu identitas di 
berbagai bidang seperti pekerjaan, agama, politik, dan peran gender (Kroger, 2003; Marcia, 1966, 1980; Muuss 1996. Mereka mengevaluasi secara kritis nilai-nilai identitas sebelumnya dan menghilangkan hal-hal yang tidak sesuai dengan pribadinya (Marcia, 1966). Remaja Foreclosure tidak mengalami krisis identitas atau periode eksplorasi, namun mereka telah memutuskan aspirasi, nilai-nilai, dan keyakinan yang sangat dipengaruhi oleh harapan orang tua (Marcia, 1966, 1980). Tanpa periode eksplorasi, remaja Foreclosure berisiko prematur dalam membuat komitmen terhadap serangkaian nilai tanpa berlanjut ke status identitas achievement (Muuss, 1996). Remaja dalam status Moratorium menjalani tahap eksplorasi dengan melakukan percobaan dengan berbagai alternatif peran dan keyakinan (Marcia, 1966, 1980). Mereka belum membuat komitmen yang tetap melainkan baru komitmen sementara yang dapat diubah dan dimodifikasi sesuai dengan proses eksplorasi identitas yang dilakukannya (Kroger, 2003). Remaja pada status identitas Diffusion mungkin pernah maupun tidak pernah mengalami krisis identitas atau eksplorasi diri (Marcia, 1966, 1980). Namun, mereka menampilkan kurangnya komitmen untuk pilihan identitas (Berzonsky \& Adams, 1999). Mereka umumnya mengungkapkan ketidakpedulian terhadap proses pembentukan identitas dan sering melihatnya sebagai sesuatu yang tidak bermakna atau tidak menarik (Marcia, 1966).

Identitas senantiasa melekat dengan konteks tertentu dari indvidu, antara lain pada konteks budaya. Konstruk budaya berkontribusi secara signifikan terhadap pekembangan identitas individu. Guru yang kompeten harus mempertimbangkan masalah identitas budaya tidak hanya yang berkaitan dengan peserta didik, tetapi juga yang berkaitan dengan diri mereka sendiri. Kesadaran diri tentang perkembangan identitas ras dan etnis seseorang harus tercermin dalam interaksi guru-siswa dalam pembelajaran (Moore-Thomas, 2012).

Untuk memahami suatu unsur-unsur budaya diperlukan adanya penjelasan mengenai definisi khusus tentang budaya dan kebudayaan. Secara etimologi, budaya terdiri dari serangkaian kata yang berarti budhi dan daya. Budhi yang berarti akal murni, dan daya yang berarti usaha. Sementara itu, kebudayaan merujuk pada kemampuan budaya dalam mempertahankan kebenaran yang dianggapnya benar (Asy'arie, et al. 1988, p. 66). Karena akal dan budi manusia itu berbeda antara satu kelompok dengan yang kainnya, maka berbeda pula kekhasan budayanya. Bahkan bisa juga terjadi perbedaan antar individu dalam 
kelompoknya. Kekhasan dalam keberagaman inilah yang nantinya akan membentuk identitas budaya seseorang atau kelompok orang.

Makna identitas budaya seringkali dikacaukan dengan istilah identitas sosial. Identitas sosial terbangun dari struktur sosial yang dibentuk dalam sebuah masyarakat. Sedangkan identitas budaya terbentuk melalui struktur kebudayaan suatu masyarakat. Dengan kata lain struktur budaya adalah pola-pola persepsi, berpikir dan perasaan, sedangkan struktur sosial adalah pola-pola perilaku sosial (Bekker, 1984, p. 47). Identitas budaya sejatinya terdiri atas dua hal, yaitu identitas individual dan identitas komunal. Identitas individual diperoleh seseorang sejak lahir maupun dari proses interaksi yang dialami mulai dari lahir, sedangkan identitas komunal merupakan suatu karakteristik yang menggambarkan ciri-ciri dari suatu kelompok atau koloni yang menunjukkan secara utuh tentang karakteristik koloni itu (Ihromi, 1996, p. 24). Dengan demikian, identitas budaya dapat dimaknai sebagai tinggi-rendahnya eksplorasi dan komitmen seseorang tentang

Seperti telah disinggung dalam uraian seblumnya, istilah budaya pertama muncul dalam sebuah kamus Inggris tahun 1920-an. Dalam Bahasa Inggris, budaya merupakan padanan kata culture yang diartikan sebagai "advanced development of the human powers; development of the body, mind and spirit by training and experience" (Hornby, 1982). Sedangkan dalam suatu karya antropologi penggunaan kata culture pertama dilakukan oleh Tylor (1971). Ia membatasi budaya sebagai keseluruhan kompleks yang terdiri dari pengetahuan, keyakinan, seni, moral, hukum, adat kebiasaan dan kapabilitas lain, serta kebiasaan apa saja yang diperoleh seorang manusia sebagai anggota suatu masyarakat.

Menurut para ahli sosiologi-antropologi budaya, isu pengkajian budaya dapat dilacak dari dua dimensi (Warnaen, 1998; Gharna, 1990), yaitu: (1) merujuk kepada hasil kajian pustaka yang bersangkut paut dengan keberadaan masyarakat, yakni manusia dan lingkungannya; dan (2) kajian lapangan para peneliti beserta referensinya tentang adat instiadat masyarakat beserta kebudayaannya. Dalam penelitian ini, kedua dimensi tersebut digunakan secara simultan dan kompelementer.

Para sarjana antropologi mengungkapkan bahwa dalam kebudayaan manusia merkipun beragam ternyata di dalamnya mengandung unsur-unsur yang universal, artinya unsur-unsur kebudayaan yang bisa didapat dalam semua kebudayaan di manapun di dunia. Unsur-unsur ini disebut cultural universals. 
Sedangkan Murdock (1945) menyebut unsur-unsur itu common domination of culture. Mengenai apakah yang dapat disebut cultural universals itu, ada beberapa pandangan di antara para sarjana antropologi. Pandangan yang berbeda-beda itu serta alasan-alasannya diuraikan oleh Kluckhohn dalam sebuah karangan bernama Universal Categories of Culture (1953). Dengan mengambil inti dari berbagai macam skema tentang cultural universals yang disusun oleh beberapa orang sarjana itu, maka kita dapat menganggap tujuh unsur kebuduayaan sebagai kultural universals yang bisa didapatkan pada semua masayarakat di dunia, ialah: (1) sistem peralatan dan perlengkapan hidup, (2) sistem mata pencaharian hidup, (3) sistem kemasyarakatan, (4) bahasa, (5) kesenian, (6) sistem pengetahuan, dan (7) sistem religi.

Unsur-unsur kebudayaan yang universal tersebut itu dapat dianggap juga sebagai isi dari kebudayaan manusia pada umumnya, dan dengan demikian dapat kita sebut pokok-pokok atau subjek-subjek dari etnologi. Memang kalau kita berikan sebagian besar dari kitab-kitab etnografi yang memberikan pelukisan tentang kebudayaan sesuatu suku bangsa, maka ketujuh unsur tersebut di atas itulah yang menjadi pokok-pokok pembicaraan. Sudah barang tentu pokok-pokok pembicaraan etnologi menjadi juga pokok-pokok pembicaraan antropologi sosial.

Tiap pokok khusus dari etnologi antropologi sosial tersebut dibagi ke dalam berbagai pokok khusus lagi. Pokok-pokok khusus itu merupakan rincian lebih lanjut dari ketujuh cultural universals tadi. Sistem peralatan dan perlengkapan hidup manusia, terdiri dari alat-alat produktif, alat-alat distribusi dan transpor, wadah-wadah dan tempat-tempat untuk menaruh, makanan dan minuman, tempat berlindung dan perumahan, dan senjata. Sistem mata pencaharian hidup, terdiri dari atas berburu dan meramu, perikanan, bercocok tanam di ladang, bercocok tanam tidak tetap, peternakan, dan perdagangan. Sistem kemasyarakatan, terdiri atas sistem kekerabatan, sistem kesatuan hidup setempat, asosiasi dan perkumpulan-perkumpulan, sistem kenegaraan. Bahasa terdiri dari bahasa lisan dan bahasa tertulis. Kesenian terdiri atas seni patung, seni relief, seni lukis dan gambar, seni rias, seni vokal, seni instrumental, seni kesusasteraan, dan seni drama. Sistem pengetahuan, terdiri dari: pengetahuan tentang sekitaran alam, pengetahuan tentang alam flora, pengetahuan tentang alam fauna, pengetahuan tentang zat-zat dan bahan-bahan mentah, pengetahuan tentang tubuh manusia, pengetahuan tentang kelakuan sesama manusia, pengetahuan tentang ruang, waktu, dan bilangan. Sedangkan sistem religi dan kehidupan kerohanian, terdiri dari sistem kepercayaan, kesusasteraan suci, 
sistem upacara keagamaan, komunitas keagamaan, ilmu gaib, dan sistem nilai dan pandangan hidup. Penelitian ini mengkaji identitas budaya dalam kaitannya dengan perspektif Marcia (1993) dikombinaskan dengan perspektif Murdock (1945) terkait dengan common domination of culture. Hal ini agak berbeda dengan kajian identitas kultural lainnya yang menekankan kepada identitas etnik. Dalam penelitian ini, kultur dipandang sebagai salah satu domain dari pembentukan identtas.

Terkait dengan orientais nilai rujukan, antara lain dapat dikaji berdasarkan teori orientasi nilai dari Spanger. Pemahaman terhadap teori Spranger tidak dapat dilepaskan dari pemikiran terdahulu dari mana teori tersebut berakar. Teori Spranger beaker dari paham Neokantialisme. Dari sekian mazhab Neokantialisme, mzhab Baden lah yang paling berpengaruh terhadap teori Spranger (Edward dalam Kartadinata, 1998). Menurut Spranger, hampiran psikologis terhadap kehidupan manusia tidak dilakukan dengan abstraksi ilmu pengetahuan melainkan dengan perspektif dan apresiasi nilai-nilai budaya. Kepribadian manusia terbentuk dan berakar pada tatanan nilai-nilai budaya dan kesejarahan. Walaupun demikian, Spranger tetap mengakui kekuatan individual yang ia sebut roh subjektiuf (subjentive spirit). Sementara itu, kekuatan nilai budaya merupakan roh objektif (objective spirit). Spranger mendudukan roh subjektif ini dalam posisi primer, karena nilai-nilai budaya hanya akan berkembang dan bertahan apabila didukung dan dihayati oleh individu (Edward dalam Kartadinata, 1998). Manusia tidak menerima nilai secara pasif melainkan secara aktif dan kreatif. Kedua roh itu berhubungan timbale balik. Roh objektif akan berkembang jika didukung oleh roh subjektif, sementara itu roh subjektif terbentuk dan berkembang dengan berpedoman pada roh objektif sebagai citacita yang harus dicapai atau diwujudkan.

Spranger memandang kebudayaan sebagai system nilai, dan dia menggolongkan nilai budaya itu ke dalam enam jenis nilai, yaitu nilai teori, ekonomi, seni, agama, social, dan politik. Empat nilai pertama (teori, ekonomi, seni, agama), digolongkan oleh Spranger ke dalam nilai yang berkenaan dengan manusia sebagai individu, sedangkan dua nilai terakhir (social, dan politik) adalah nilai yang berkaitan dengan manusia sebagai anggota masyarakat (Suryabrata dalamKartadinata, 1998). Keenam nilai tersebut merupaka refleksi dari perkembangan roh subjektif yang berpedoman kepada roh objektif. Atas dasar pemikiran tersebut, Spranger merumuskan tipologi manusia ke dalam enam jenis kepribadian sesuai dengan jenis-jenis nilainya. 
Penggolongan manusia ke dalam enam tipe kepribadian itu, menurut Spranger, hanya merupakan penggolongan ideal. Dalam kenyataannya semua nilai itu ada dalam diri manusia, walaupun nilai yang satu lebih dominan dari nilai lainnya. Spranger tetap mengakui kebebasan individu dalam memilih nilai. Tanggung jawab mewujudkan nilai itu tetap ada pada diri individu: tidak ada isi budaya yang menjadi bermakna kecuali sejauh nilai-nilai itu tampil dari sikap dan kata hati jiwa manusia.

\section{METODE}

Penelitian ini mengkaji masalah yang sedang terjadi pada saat penelitian dilakukan. Data penelitian diperoleh berdasarkan satu kali survai dengan menggunakan kuesioner Selanjutnya data tersebut dijadikan dasar untuk mendeskripsikan karakteristik masalah yang dikaji. Sehubungan dengan hal itu maka metode yang digunakan dalam penelitian ini adalah deskriptif (Santrock, 1977, p. 56). Sedangkan desain penelitian yang digunakan dalam penelitian ini adalah cross sectional survey (Shaugnessy \& Zechmeister, 1994: 129; Lerner \& Hultsch, 1983, p. 25) dengan pendekatan kuantitatif.

Subjek penelitian untuk kepentingan analisis orientasi nilai rujukan dan perkembangan identitas vokasinal dalam rangka identifikasi untuk pengembangan model, adalah mahasiswa baru program kependidikan sebanyak 96 orang yang dipilih secara acak dengan menggunakan teknik multi stage cluster sampling. Hasil verifikasi terhadap 96 subjek yang mengisi kuesioner, diperoleh 81 subjek yang memadai untuk dinanalisis lebih lanjut.

Dalam penelitian ini, status identitas kultural, merujuk kepada konsep Marcia dan Murdock, diartikan sebagai cara atau gaya menghadapi resolusi isu identitas yang didasarkan kepada tinggi atau rendahnya eksplorasi dan komitmen dalam domain kultural. Eksplorasi merujuk kepada sejauhmana remaja mengalami proses pencarian informasi terhadap berbagai alternatif yang terkait dengan isu kultural. Sedangkan komitmen mengacu kepada suatu penentuan sikap atau pengambilan keputusan mengenai isu kultural dan keterlibatan dalam aktivitas yang bermakna ke arah implementasi pilihan tersebut dalam kitannya dengan isu kultural. Atas dasar itu, status identitas dipilahkan ke dalam empat kategori yaitu: Identity Achievement, Moratorium, Foreclosure, dan Indentity Diffusion. Identity Achievement adalah individu yang mengalami proses eksplorasi dan telah berhasil mengatasinya, sehingga ia telah sampai kepada suatu komitmen pribadi. Moratorium adalah individu yang sangat intens menjalani eksplorasi. 
Ia secara aktif bereksplorasi dan mencari alternatif serta berjuang untuk menemukan identitas, namun belum sampai kepada komitmen. Kalaupun tampak ia memiliki komitmen, namun komitmen yang dikembangkannya itu masih belum jelas. Foreclosure adalah individu yang tidak pernah mengalami eksporasi tetapi telah memiliki komitmen. Komitmen itu bukan diperoleh melalui proses pencarian maupun eksplorasi, namun diperolehnya dari orang tua atau orang lain. Indentity Diffusion adalah individu yang tidak pernah atau belum mengalami eksplorasi identitas sehingga tidak pernah membuat suatu komitmen. Instrumen pengungkap data identitas kultural dikembangkan dalam penelitian ini terdiri atas 56 pernyataan dengan skala sembilan. Sementara itu, orientasi nilai rujukan mengacu pada teori Spranger. Untuk mengungkap data orientasi nilai rujukan akan digunakan IONIR yang dikembangkan Kartadinata (1998). Data penelitian dianalisis melalui pendekatan kuantitatif denga menggunakan teknik stattistik.

\section{HASIL DAN PEMBAHASAN}

Hasil analisis data terkait dengan status identitas kultural mahasiswa calon guru, menunjukkan informasi sebagai mana disajikan pada Tabel 1.

Tabel 1. Peta Status Identitas Kultural Mahasiswa Calon Guru

\begin{tabular}{lccc}
\hline Status Identitas Vokasional & Kode & $\mathrm{F}$ & $\%$ \\
\hline Achievement & $\mathrm{A}$ & 19 & 23.46 \\
\hline Moratorium & $\mathrm{M}$ & 18 & 22.22 \\
\hline Forecloser & $\mathrm{F}$ & 15 & 18.52 \\
\hline Difffusion & $\mathrm{D}$ & 24 & 29.63 \\
\hline Ach-Mor & $\mathrm{AM}$ & 2 & 2.47 \\
\hline Ach-Fore & $\mathrm{AF}$ & 2 & 2.47 \\
\hline Ach_diff & $\mathrm{AD}$ & 1 & 1.23 \\
\hline & & 81 & 100.00 \\
\hline
\end{tabular}

Tabel 1 menunjukkan bahwa sebagian besar mahasiswa calon guru $(51,85 \%)$ berada pada status identitas kultural yang rendah, yakni forecloser dan diffusion. Status achievement dan moratorium, yang ditengarai sebagai stastus identitas yang tinggi, masing-masing dimiliki hanya oleh kurang dari seperempat jumlah mahasiswa.

Terkait dengan nilai rujukan dan status identitas kultural mahasiswa calon guru, dapat disimak pada Tabel 2. 
Tabel 2. Peta Orientasi Nilai Rujukan Mahasiswa Calon Guru

\begin{tabular}{lccc}
\hline \multicolumn{1}{c}{ Orientasi Nilai Rujukan } & Kode & $\mathrm{f}$ & $\%$ \\
\hline Ekonomi & $\mathrm{E}$ & 27 & 33.33 \\
\hline Keilmuan & $\mathrm{I}$ & 16 & 19.75 \\
\hline Sosial & $\mathrm{S}$ & 14 & 17.28 \\
\hline Kekuasaan & $\mathrm{K}$ & 8 & 9.88 \\
\hline Estestik & $\mathrm{ES}$ & 7 & 8.64 \\
\hline Religius & $\mathrm{R}$ & 9 & 11.11 \\
\hline Jumlah & & 81 & 100.00 \\
\hline
\end{tabular}

Tabel 2 mengisyaratkan bahwa empat nilai yang menjadi rujukan paling kuat bagi para mahasiswa calon guru adalah nilai ekonomi, keilmuan, sosial, dan religius. Sementara itu, nilai kekuasaan dan estetik kurang menjadi kepedulian mahasiswa dalam menentukan rujukan nilai.

Berdasarkan hasil analisis menggunakan tabulasi silang, diperoleh konfigurasi nilai rujukan dalam formasi status identitas kultural mahasiwa calon guru disajikan pada Tabel 3 .

Tabel 3. Konfigurasi Nilai Rujukan dalam Formasi Status Identitas Kultural

\begin{tabular}{lccccccr}
\hline \multirow{2}{*}{ Status } & \multicolumn{7}{c}{ Orientasi Nilai } \\
\cline { 2 - 7 } & $\mathrm{E}$ & $\mathrm{I}$ & $\mathrm{S}$ & $\mathrm{K}$ & $\mathrm{ES}$ & $\mathrm{R}$ & \multirow{2}{*}{ Jumlah } \\
\hline $\mathrm{A}$ & 2.47 & 14.81 & 2.47 & 0.00 & 0.00 & 3.70 & 23.46 \\
\hline $\mathrm{M}$ & 7.41 & 2.47 & 4.94 & 0.00 & 3.70 & 3.70 & 22.22 \\
\hline $\mathrm{F}$ & 11.11 & 0.00 & 4.94 & 2.47 & 0.00 & 0.00 & 18.52 \\
\hline $\mathrm{D}$ & 9.88 & 0.00 & 4.94 & 7.41 & 4.94 & 2.47 & 29.63 \\
\hline $\mathrm{AM}$ & 0.00 & 2.47 & 0.00 & 0.00 & 0.00 & 0.00 & 2.47 \\
\hline $\mathrm{AF}$ & 2.47 & 0.00 & 0.00 & 0.00 & 0.00 & 0.00 & 2.47 \\
\hline $\mathrm{AD}$ & 0.00 & 0.00 & 0.00 & 0.00 & 0.00 & 1.23 & 1.23 \\
\hline Jumlah & 33.33 & 19.75 & 17.28 & 9.88 & 8.64 & 11.11 & 100.00 \\
\hline
\end{tabular}

Tabel 3 mengisyaratkan bahwa mahasiswa calon guru yang berstatus identitas kultural achievement memiliki orientasi yang kuat pada nilai keilmuan, kemudian nilai religius, serta nilai sosial dan nilai ekonomi. Status moratorium lebih kuat berieotasi pada nilai ekonomi, sosial, estetis dan religius, serta terakhir keilmuan. Status foreclosure lebih berorientasi pada nilai ekonomi, sosial, dan kekuasaan. Sedangkan status diffusion lebh berorientasi pada nilai ekonomi, kekuasaan, sosial dan estesis, serta religius. Selain itu ada 6,17\% yang memiliki status identtas ganda, yaitu achievement-moratorium beroriantasi 
pada nilai ekeilmuan, achievement-foreclosur berorientasi pada nilai ekonomi, dan achievement diffusion berorientasi pada nilai religius.

Dalam penelitian ini terungkap bahwa sebagian besar mahasiswa calon guru $(51,85 \%)$ berada pada status identitas kultural yang rendah, yakni forecloser dan diffusion. Temuan ini mengandung makna bahwa mereka yang Foreclosure tidak pernah mengalami eksporasi tetapi telah memiliki komitmen tentang isu kultural. Komitmen itu bukan diperoleh melalui proses pencarian maupun eksplorasi, namun diperolehnya dari orang tua atau orang dewasa lain. Sementara itu mahasiswa yang berstatus Indentity Diffusion tidak pernah atau belum mengalami eksplorasi identitas sehingga tidak pernah membuat suatu komitmen.

Posisi sebagian besar mahasiswa pada status forecloser dan diffusion mengindikasikan bahwa mereka berstatus identitas rendah. Identitas seperti ini menururt Erikson merupakan salah satu permasalahan dalam perkembangan identitas. Sehubungan itu maka mereka perlu dibantu sehingga mampu melakukan eksplorasi dan komitmen secara memadai. Eksplorasi merujuk kepada sejauhmana mahasiswa mengalami proses pencarian informasi terhadap berbagai alternatif yang terkait dengan isu kultural. Sedangkan komitmen mengacu kepada suatu penentuan sikap atau pengambilan keputusan mahasiswa mengenai alternatif dan keterlibatan dalam aktivitas yang bermakna ke arah implementasi pilihan tersebut dalam kitannya dengan isu pilihan kultural.

Mengacu pada pendapat Marcia et al (1993, pp. 206-211) sebagaimana telah diungkapkan dalam uraian sebelumnya, proses eksplorasi ditandai oleh sejauhmanakah mereka melakukan penjajagan terhadap berbagai hal yang berkenaan dengan domain topik identitas sebagaimana direfleksikan oleh keluasan dan kedalaman aspek knowledgeability, activity directed toward gathering information, considering alternative potential identity elements, dan desire to make an early decision. Keempat aspek tersebut dapat dijelaskan sebagai berikut.

Pertama, kemampuan mengetahui ditunjukkan oleh banyak sedikitnya informasi yang berhasil dihimpun dan dipahami menyangkut berbagai alternatif potensial pada domain identitas kultural. Inti dari knowledgeability dapat dilihat dari keluasan dan kedalam pengetahuan remaja tentang berbagai alternatif bidang identitas yang sedang dieksplorasi. 
Kedua, aktivitas yang terarah untuk mengumpulkan informasi ditunjukkan dengan berbagai kegiatan yang memadai untuk mengumpulkan informasi dalam rangka memperluas dan memperdalam pengetahuan yang dibutuhkan untuk mencapai suatu keputusan di antara berbagai alternatif yang ada. Aktivitas yang tertuju pada pengumpulan informasi ini dapat meliputi introspeksi, mengamati orang lain, diskusi dengan berbagai sumber, dapat juga dengan cara membaca, menonton televisi, bekerja pada pekerjaan yang representatif, dan menyalurkan hobby yang sesuai. Pada remaja akhir, inti persoalannya adalah bahwa aktivitas itu harus dilakukan yang bersangkutan atas inisiatif sendiri, bukan karena ajakan atau pengaruh orang lain.

Ketiga, mempertimbangkan alternatif elemen identitas yang potensial mengacu pada kemampuan individu menyadari dengan jeli berbagai kemungkinan atau peluang dan dapat menggambarkan keuntungan dan kerugian dari setiap alternatif dengan pertimbangan yang mendalam. Remaja merupakan suatu periode dalam lintasan hidup dimana orang dapat mentolerir terjadinya eksperimentasi dan bahkan kadang-kadang mendorong remaja untuk melakukannya. Dengan uji coba itu remaja dapat mengarahkan kemampuannya untuk mempertimbangkan berbagai alternatif dalam menentukan pilihan.

Kelima, keinginan untuk membuat keputusan secara dini adalah penggunaan prinsip kekinian atau kesegeraan dalam membuat keputusan. Kebanyakan remaja ingin membuat suatu keputusan sesegera mungkin agar dapat mengimple-mentasikannya secara konsisten sesuai jati dirinya. Pernyataan tidak tegas akan berakibat ketidaknyamanan bagi mereka. Keadaan tidak menyenangkan sehubungan dengan krisis identitas ini mendorong remaja untuk segera memecahkan ketidakjelasan secara realistik.

Sementara itu tingkat komitmen ditunjukkan oleh sejauh mana keteguhan pendirian mahasiswa itu terhadap domain topik identitas sebagaimana direfleksikan oleh keluasan dan kedalaman aspek: knowledgeability, activity directed toward implementing the chosen identity element, emotional tone, identification with significant other, projecting one's personal future, dan resistance to being swayed. Penjelasan keenam aspek tersebut diungkapkan sebagai berikut.

1) Kemampuan mengetahui mengacu pada pengetahuan berhubungan dengan kemampuan untuk menjelaskan hal-hal yang diputuskan. Pengetahuan yang menyangkut komitmen pilihan remaja dapat diperoleh dari anggota keluarga, teman sebaya, para guru, media, dan pengalaman pribadi. Remaja 
yang telah komit terhadap karier, mampu memahami lebih rinci aspek-aspek pilihan domain identitas. Remaja yang siap ambil bagian dalam suatu bidang yang sesuai dengan komitmennya mampu menunjukkan dengan nyata pengetahuan yang lebih banyak daripada mereka yang pasif.

2) Aktivitas yang terarah pada penerapan elemen identitas yang dipilih merupakan persiapan untuk menjalankan peran-peran kehidupan di masa datang pada elemen identitas. Aktivitas yang mengarah pada penerapan elemen identitas yang dipilih dapat berupa diskusi dengan orang yang berpengetahuan banyak tentang bidang yang dipilih, membaca tema-tema bidang pilihan tersebut, mengunjungi tempat-tempat yang relevan, berteman dengan orang yang berorientasi sama, mengikuti latihan, menekuni peker-jaan paruh waktu yang cocok dengan pilihan, dan menekuni hobby. Jadi, remaja kahir yang telah memutuskan pilihan dalam suatu bidang, idealnya senantiasa berusaha melakukan hal-hal yang perlu untuk mengaktualisasi-kan pilhan tersebut.

3) Nada emosi merupakan ekspresi perasaan-perasaan yang memantulkan rasa percaya diri, mantap, dan optimis tentang masa depannya, meskipun sering disadari bahwa kesulitan dapat muncul dalam penerapan pilihan tersebut. Pada umumnya orang yang memiliki komitmen identitas akan menunjukkan reaksi stres yang situasional dan tidak menunjukkan reaksi emosional yang berlebihan.

4) Mengidentifikasi model atau figur yang berpengaruh kuat terhadap pilihan komitmen mereka dengan cara menyaring terlebih dahulu berbagai model yang berbeda, kemudian menggabungkan dalam cara-cara baru dan unik sehingga bermanfaat bagi perkembangan ego mereka.

5) Memproyeksikan masa depan pribadi tercermin dalam kemampuan memproyeksikan karakterisktik pribadi terhadap masa depan dan menggambarkan bermacam aktivitas yang akan dilakukannya. Remaja yang memiliki komitmen mampu mempertautkan rencananya dengan aspek lain dari kehidupan masa depan sebagaimana mereka impikan, meskipun ada sedikit kerisauan tentang implikasi keputusan penting bagi masa depannya.

6) Daya tahan terhadap goyangan merujuk pada ketahanan individu terhadap godaan-godaan yang mengalihkan pilihan mereka. Komitmen berarti kesetiaan yang tangguh untuk mempertahankan pilihan, meskipun digoyang oleh rayuan yang menggiurkan. Orang yang komit tak akan mudah 
mengkhianati pilihannya, sekalipun dia tahu bahwa di kemudian hari akan datang tawaran lain yang jauh lebih menguntungkan.

Masa remaja akhir dibanding dengan masa-masa sebelumnya, kemantapan komitmen merupakan suatu kebutuhan yang lebih mendasar, karena untuk memasuki ambang pintu dewasa, remaja dituntut menunjukkan kemandiri-an dalam mengambil keputusan penting yang menyangkut segi-segi kehidupannya (Adolsen, 1980; Rice, 1996). Remaja yang tidak mampu menegakkan komitmen dalam berbagai bidang kehidupan akan terombang-ambing dalam menghadapi realitas kehidupan orang dewasa dan terus menerus berada dalam ketidakpastian.

Berkenaan dengan pola universal kebudayaan yang dikaji dalm penelitian ini yang mengacu pada teori Murdock, seyogianya tidak dipahami sebagai satusatunya teori. Teori lain, sebagaimana diungkapkan oleh Wissler (Roucek \& Warren, 1984) disebutkan ada sembilan aspek budaya, yaitu pertuturan, sifat kebendaan, kesenian, dongeng dan pengetahuan ilmiah, praktik-paraktik keagamaan, keluarga dan sistem sosial, harta, negara, dan peperangan. Lebih lanjut diungkapkan bahwa, dalam rangka analisis kebudayaan, peneliti dapat memusatkan kajiannya pada sifat, kompleks, kawasan, dan tema atau pola kebudayaan.

Bagaimana identitas kultural itu dibina dan dikembangkan antara lain dapat dikaji melalui konsep UNESCO. Perhatian terhadap pentingnya pembinaan nilai budaya masyarakat dalam pembangunan, dilandasi oleh pemikiran dan pengalaman para pakar dari negara-negara anggota UNESCO di kawasan AsiaPasifik yang mengakui bahwa modernisasi dan urbanisasi yang pesat sekarang ini merupakan urusan utama yang dihadapi oleh kawasan Asia-Pasifik karena menghasilkan kemajuan ekonomi dan teknologi yang lebih cepat daripada pembangunan sosial dan budaya.

Pendidikan yang memainkan peranan fundamental untuk pembangunan pribadi dan sosial, telah dimanfaatkan untuk menciptakan angkatan kerja yang lebih terampil, tetapi sering atas pengorbanan pembangunan seluruh pribadi. Akibatnya, tujuan-tujuan jangka panjang dari nilai-nilai manusia dan prinsipprinsip moral cenderung menjadi kurang penting pada waktu mereka harus bersaing dengan pertimbangan-pertimbangan ekonomis yang bersifat lebih segera. Di lain pihak, banyak negara di kawasan Asia-Pasifik ini yang masih dalam proses demokrasi dan menuntut usaha sunggguh-sungguh dalam menyebarluaskan prinsip-prinsip nilai universal, seperti hak-hak asasi manusia 
untuk semua dan dalam promosi kebudayaan perdamaian dan toleransi. Untuk itu maka pendidikan untuk perdamaian, hak-hak asasi manusia, dan demokrasi (pendidikan internasional dan nilai-nilai) seyogianya mendapatkan perhatian dan prioritas lebih besar (UNESCO PROAP, 1998).

Alasan lain mengenai perlunya pembinaan nilai budaya dalam rangka pembangunan, mengacu kepada mandat asli UNESCO yaitu perdamaian untuk pembangunan dan pembangunan untuk perdamaian, dengan misi aslinya adalah transformasi kebudayaan peperangan dan kekerasan ke kebudayaan perdamaian, terutama melalui pendidikan dan pembinaan nilai-nilai (UNESCO PROAP, 1998). Untuk proses transformasi tersebut, para pakar dari sembilan negara kawasan Asia-Pasifik dalam wadah Asia-Pacific Network for International Education and Value Education (APNIEVE) yang bertemu di Malaka tanggal 1-4 Juli 1996, berhasil mengkaji nilai-nilai universal yang diperlukan untuk hidup bersama dalam damai dan harmoni, khususnya untuk konteks Asia-Pasifik. Nilai-nilai dimaksud mencakup empat nilai inti, yaitu perdamaian, hak-hak asasi manusia, demokrasi, dan pembangunan berkelanjutan. Masing-masing nilai inti tersebut disertai oleh sejumlah nilainilai terkait yang mendukungnya. Dalam perspektif Asia-Pasifik, untuk hidup bersama dalam damai dan harmoni, diperlukan empat nilai inti dan sejumlah nilai terkait pendukungnya. Keempat nilai inti tersebut adalah perdamaian, hakhak asasi manusia, demokrasi, dan pembangunan berkelanjutan.

Dalam penelitian ini juga terungkap bahwa nilai rujukan paling kuat bagi para mahasiswa calon guru adalah nilai ekonomi, keliman, sosial, dan religius. Temuan ini mengandung arti bahwa mahasiswa dalam bekerja nanti cenderung mempertimbangkan untuk rugi secara ekonomi. Hal ini sesuai dengan beberapa hasil penelitian sebelumnya di Kota Bandung yang dilakukan oleh Kartadinata (1988) dan Supriadi (1991) dimana Universitas Pendidikan Indonesia (UPI) merupakan salah satu perguruan tinggi (PT) Negeri yang disurvei.

Hasil penelitian Kartadinata (1988, pp. 193-194) antara lain menunjukkan bahwa "meskipun nilai ekonomi, di mana perilaku dasarnya adalah bekerja, menduduki urutan pertama dalam arah orientasi mahasiswa PT Negeri dan Swasta di Kota Bandung, namun ternyata hal itu belum merupakan nilai yang bermakna”. Simpulan tersebut diperkuat dengan temuan penelitian Supriadi (1991, p. 18) tentang subkultur mahasiswa PT Negeri dan Swasta di Kota Bandung yang dikategorisasikan ke dalam vokasional, akademik, kolegiat, politik, dan nonkonformis. Dari hasil penelitian itu antara lain terungkap bahwa 
“orientasi vokasional mahasiswa pada umumnya baru termasuk kategori cukup. Dilihat dari intensitas orientasinya, mereka menempatkan subkultur vokasional pada prioritas keempat setelah subkultur akademik, politik, dan kolegiat yang kemudian diakhiri dengan subkultur nonkonformis".

Dikaitakan dengan teori Spranger yang memandang kebudayaan sebagai sistem nilai, yaitu nilai teori,/keilmuan ekonomi, seni, agama, social, dan politik, apa yang terungkap dalam penelitian ini, mahasiswa termasuk ke dalam empat nilai pertama (keilmuan, ekonomi, seni, agama) yang digolongkan oleh Spranger ke dalam nilai yang berkenaan dengan manusia sebagai individu. Mahasiswa tampaknya belum begtu mementingkan dua nilai terakhir (sosial dan politik/kekuasaan) yang menurut Spranger merupakan nilai yang berkaitan dengan manusia sebagai anggota masyarakat (Kartadinata, 1998).

Perlu dipahami bahwa penggolongan manusia ke dalam enam tipe orientasi nilai menurut Spranger, yang nantinya akan membentuk kepribadian, hanya merupakan penggolongan ideal. Dalam kenyataannya semua nilai itu ada dalam diri manusia, walaupun nilai yang satu lebih dominan dari nilai lainnya. Spranger tetap mengakui kebebasan individu dalam memilih nilai. Tanggung jawab mewujudkan nilai itu tetap ada pada diri individu: tidak ada isi budaya yang menjadi bermakna kecuali sejauh nilai-nilai itu tampil dari sikap dan kata hati jiwa manusia. Dengan demikian, apa yang terungkap dalam penelitian ini tampaknya masih sesuai dengan apa yang diteorikan oleh Spranger. Tantangan untuk kajian lebih lanjut adalah nilai-nilai mana yang secara empirik diperlukan utuk menunjang keberhasilan kinerja profesional seorang konselor.

Temuan lain penelitian ini mengindikasikan bahwa mahasiswa yang memiiki status identitas kultural tinggi memiliki orientasi yang kuat pada nilai keilmuan, kemudian nilai religius, sosial, ekonomi, dan estetis. Status identitas yang rendah lebih berorientasi pada nilai ekonomi, sosial, dan kekuasaan. Jika dikaitkan dengan teori Spranger, temuan penelitian mengindikasikan bahwa mahasiswa yang memiliki status identitas kultural tinggi cenderung berorientas pada nilai manusia sebagai individu dan kemudian nilai manusia sebagai masyarakat. Sebaliknya, mahasiswa yang memiliki status identitas rendah, lebih mengutamakan nilai yang berkaitan dengan manusia sebagai anggota masyarakat bartu kemudian berorientasi pada pada nilai manusia sebagai individu. Hal ini memperkuat konep Erikson dan Marcia bahwa identitas pada hakekatnya adalah interseksi antara individu dengan masyarakat. 


\section{SIMPULAN}

Sesuai dengan permasalahan, analisis data, dan pembahasan, hasil penelitian ini dirumuskan dalam simpulan bahwa identitas kultural mahasiswa calon guru masih menyebar dengan proporsi terbesar pada status identitas yang rendah. Demikian halnya dengan orientasi nilai rujukan mahasiswa yang juga masih menyebar pada berbagai nilai. Prioritas orientasi terletah pada nilai ekonomi, keilmuan, sosial, dan religius. Mahasiswa yang memiiki status identitas kultural tinggi cenderung berorientasi pada nilai manusia sebagai individu dan kemudian nilai manusia sebagai masyarakat. Sebaliknya, mahasiswa yang memiliki status identitas rendah, lebih mengutamakan nilai yang berkaitan dengan manusia sebagai anggota masyarakat baru kemudian berorientasi pada pada nilai manusia sebagai individu.

Penelitian ini menyimpulkan bahwa status identitas kultural mahasiswa calon guru masih tergolong rendah. Padahal, status identitas yang tinggi sangat penting dimiliki oleh guru untuk menampilkan kinerja secara profesional dan memiliki kehandalan dalam berkompetisi global. Mengingat saat ini masih jarang LPTK yang menyediakan program pengembangan identitas secara khusus, maka diperlukan terobosan untukuntuk mengembangkan model yang teruji secara filosofis, konseptual, maupun empirik.

Perlu melakukan pengkajian secara mendalam berkenaan dengan nlai-nilai esensial yang sangat diperlukan untuk pengembangan kinerja seorang guru. Ini penting untuk pijakan orientasi dalam pendidikan calon guru, baik pendidikan prajabatan maupun pendidikan dalam jabatan. Selain itu dapat diketahui secara empirik apakah seorang guru harus mengutamakan nilai individu baru kemudian nilai kermasyarakatan, atau mengutamakan nilai kemasyarakatan baru kemudian nilai individu, atau justru harus berada dalam keseimbangan di antara kedau nilai orientasi tersebut.

Identitas sangat lekat dengan kepribadian, bahkan ada yang memandang identitas itu sebagai inti kepribadian. Sehubungan itu, upaya pembentukan identitas perlu dibangun di atas kerangka filosofis, konseptual, dan dukungan empirik yang memadai. Begitu juga terkait dengan sistem peluncurannya apakah melalui kurikulum tersendiri, terpadu dengan perkuliahan mata kuiah tertentu, melalui intervensi dan pembiasaan dalam kehidupan asrama, atau melalui layanan bimbingan dan konseling di PT.

Untuk pengembangan teori identitas kultural, kecenderungan arah riset identitas kini dan masa depan, fokus pada konten pada konteks identitas setelah remaja 
akhir Kajian perkembangan identitas budaya saat ini baru berkisar pada bagaimana sikap seseorang terjadap diri sendiri, orang lain pada kelompok minoritas yang sama, orang lain pada kelompok minoritas yang berbeda, dan orang lain pada kelompok yang mendominasi. Untuk pengembangan teori, kajian identitas budaya perlu diperluas pada apa yang disebut unsur-unsur utama isi dari budaya manusia pada umumnya.

Untuk praksis pendidikan guru, dalam rangka menyiapkan calon guru yang kompeten dan adaptif terhadap tuntuan belajar, permasalahan, dan kecenderungan kehidupan di Abad ke-21, proses pendidikan di LPTK tidak cukup menekankan pada penguasaan kompetensi. Lebih dari itu, pendidikan calon guru harus mampu membangun identitas personal, professional, dan kultural yang kokoh melalui pembangunan komitmen yang dilandasi oleh eksplorasi yang luas dan dalam tentang dimensi-dimensi identitas. Untuk itu diperlukan pergeseran paradigma dalam proses pendidikan calon guru bimbingan dan konseling secara substansial dari kompetensi ke formasi identitas dan secara prosedural dari pedagogik ke heutagogik. Merujuk pada teori Marcia, maka upaya pendidikan untuk mengoptimalkan status identitas kultiral seyogianya fokus pada sepuluh indikator eksplorasi dan komitmen tersebut terkait dengan domain kultural.

\section{REFERENSI}

Adelson, K. (Ed). (1980). Handbook of adolescent psychology. New York: John Wiley.

Akkerman, S. F., \& Meijer, P. (2011). Concpetualizing teacher identity: A dialogical approach. Teachers and Teacher Education, 27 (2), 308-319.

Alsup, J. (2006). Teacher identity discourse. Mahwah, NJ: Lawrence Erlbaum.

Andersen, S. M., Spielman, L. A., \& Bargh, J. A. (1992). Future-event schemas and certainty about the future: automaticity in depressives' future-event predictions. Journal of personality and social psychology, 63(5), 711.

Archer, S. L. (Ed). (1994).Interventions for adolescent identity development. London: Sage Publication.

Asy'arie, M. et al. (1988). Agama, budaya, dan pembangunan menyongsong era industrialisasi.Yogyakarta: IAIN Sunan Kalijaga.

Bakker, J. W. M. (1984). Filsafat kebudayaan: Sebuah Pengantar. Yogyakarta: Kanisius. 
Beijaard, D., Paulien, M.C., \&Verloop, N. (2004). Reconsidering research on teachers' professional identity. Teaching and Teacher Education, 20, 107228.

Beyers, W., \& Seiffge-Krenke, I. (2010). Does identity precede intimacy? Testing Erikson's theory on romantic development in emerging adults of the 21 st century. Journal of Adolescent Research, 25(3), 387-415. doi: $10.1177 / 0743558410361370$

Bourne, E. (1978a). The state of research on ego identity: A review and appraisal Part I. Journal of Youth and Adolescence, 7(3), 223-251. doi: $10.1007 / \mathrm{bf01537976}$

Bourne, E. (1978b). The state of research on ego identity: A review and appraisal Part II. Journal of Youth and Adolescence, 7(4), 371-392. doi: 10.1007/bf01537806

Conger, J. J. (1977). Adolescence and youth. New York: Helper \& Row.

Cottone, R. (2013). A paradigm shift in counseling philosophy. Counseling Today, 56(3), 55-57.

Cremers, A. (1989). Identitas dan siklus hidup manusia. Jakarta: Gramedia.

Crosier, D. (2007). Trends in european higher education, and their implications for guidance and counselling. In Willy Aastrup (ed). Guidance and counselling in Higher Education in European Union Member States. Denmark: Counselling and Support Centre, University of Aarhus and the Authors.

Cullen, J. G. (2013). Differentiating between vocations and careers. Ireland: School of Business, National University of Ireland Maynooth.

Duckworth, A. L., Quinn, P. D., \& Seligman, M. E. (2009). Positive predictors of teacher effectiveness. The Journal of Positive Psychology, 4(6), 540547.hh

Edward, A. L. (1957). Techniques of Attitude Scale Construction. New York: Appleton-Century-Crofts, Inc.

Erikson, E. H. (1968). Identity: Youth and crisis. London: Faber and Faber.

Garcia, P. (2011). Impact of teacher personality styles on academic excellence of secondary students. National Forum of Teacher Education Journal. 21 (3): $1-8$.

Griffin, P. \& Care, E. (Eds.). (2015). Assessment and teaching of 21st century skills: Methods and approach. Dordrecht: Springer.

Hambleton, R. K. (1985). Item Response Theory: Principles and Aplications. Boston: Kluwer Publishing. 
Herr, E.L. \& Crammers, S.H. (1986). Career guidance and counseling through the life span: Systematic approach. Boston: Litle, Brown Company.

Ihromi, T. O. (1996). Pokok-pokok antropologi budaya . Jakarta: Yayasan Obor

Isdjoni. (2006). Dari subtansi ke praktis: Pokok-pokok pikiran meningkatkan kualitas pendidikan. Yogyakarta: Pustaka Pelajar.

Kartadinata, S. (1988).Profil Kemandirian dan Orientasi Timbangan Sosial Mahasiswa serta Kaitannya dengan Perilaku Empatik dan Orientasi Nilai Rujukan. Disertasi. Bandung Fakultas Pascasarjana IKIP Bandung.

Kartadinata, S. (2007). Penegasan mandat kelembagaan Universitas Pendidikan Indonesia. Bandung: UPI Press.

Kartadinata, S. (2007). Rambu-rambu Penyelenggaraan Bimbingan dan Konseling dalam Jalur Pendidikan formal. Jakarta: Ditjen PMPTK Departemen Pendidikan Nasional.

Kartadinata, S. (2011). Menguak tabir bimbingan dan konseling sebagai upaya pedagogis. Bandung: UPI Press.

Kartadinata, S. (2014). Politik jati diri: Telaah filosofi dan praksis pendidikan bagi penguatan jati diri bangsa. Bandung: UPI Press.

Kartadinata, S. (2015). Pengembangan pedagogik dari perspektif pendidikan dan pendidikan guru abad ke-2. Paparan seminar internasional pedagogik ke 6 pendidikan guru sekolah dasar. Kerjasama Universitas Pendidikan Indonesia dengan Komunitas Pendidik Serantau di Bandung, tanggal 1517 September 2015.

Kluckhohn, C. (1953). Universal categories of culture. New York: McGraw Hill.

Kluckhohn, C. (1951). Values and value orientation in the theory of action. International Poisons and E. Trindis and W.W Lambert (eds).

Koentjaraningrat. (1993). Masyarakat Terasing di Indonesia. Jakarta: P.T. Gramedia Pustaka Utama.

Koentjaraningrat. (1997). Manusia dan Kebudayaan di Indonesia. Jakarta: Jambatan.

Kroger, J. (1996).Identity in adolescence:The balance between self and other $2^{\text {nd }} e d$. London \& New York: Routledge.

Leong, F. T. L. (Ed). (2008). Encyclopedia of counseling. Los Angeless: SAGE Publication, Inc.

Lerner, R. M., \& Hultsch, D.T. (1983).Human development: A life span perspective, New York: McGraw-Hill. 
Linn, R. L. \& Gronlund, N. E. (1995). Measurement and Assesment in Teaching. Ohio: Prentice-Hall, Inc.

Marcia, J. E. (1966). Development and validation of ego-identity status. Journal of Personality and Social Psychology, 3(5), 551-558.

Marcia, J. E. (1967). Ego identity status: relationship to change in selfesteem,"general maladjustment," and authoritarianism1. Journal of personality, 35(1), 118-133.

Marcia, J. E. (1980). Identity in adolescence. In J. Adelson (Ed.), Handbook of adolescent psychology (pp. 159 - 187). New York: John Wiley \& Sons.

Marcia, J. E. (1994). Ego identity and object relations. In J. M. Masling \& R. F. Bornstein (Eds.), Empirical Perspectives on Object Relations Theory (pp. 59-103). Washington DC: APA.

Marcia, J. E. et al. (1993). Ego identity, a handbook for psychososial research, New York: Springer-Verlag.

Marcia, J. E., \& Friedman, M. L. (1970). Ego identity status in college women. Journal of Personality, 38(2), 249-263.

Matsumoto, D. (2004). Pengantar psikologi lintas budaya. Yogyakarta: Pustaka Pelajar.

Munandar, A. S. (1991). Pengembangan sumber daya manusia untuk indonesia masa depan. Bandung: Mizan.

Murdock, G. P. (1945). Common dominators of culture. In R. Linton (Ed). Science of man in the world crisis. New York: Columbia University Press.

Mussen, P. H et al. (1990).Child development and personality, New York: Harper Collins Publisher.

Osipow, S. H. (1983). Theories of career development. New Jersey: PrenticeHall, Inc.

Rakhmat, C. (2006). Komunitas Sunda Pakidulan: Studi tentang pengaruh orientasi nilai budaya, paham dualistik dunia, dan kontraproses modernisasi terhadap etos kerja. Disertasi. Bandung: Program Pascasarjana Universitas Padjadjaran

Robert, T. G. (2007). Relationships Between Personality Type And Teaching Efficacy Of Student Teachers. Journal of Agricultural Education, 48(2), 92-102.

Roucek, J. S. \& Warren, R. L. (1984). Sociology: An introduction. Terjemahan Sahat Simamora. Jakarta: Bina Aksara. 
Rushton, S., Morgan, J., \& Richard, M. (2007). Teacher's Myers-Briggs personality profiles: Identifying effective teacher personality traits. Teaching and Teacher Education, 23(4), 432-441.

Santrock, J. W. (1985). Adult development and aging. Iowa: Wm. C. Brown.

Santrock, J. W. (1997). Life-span development, Dubuque USA: Brown and Benchmark.

Shaughnessy, J. J., \& Zechmeister, E. B. (1994). Research methods in psychology, New York: McGraw-Hill

Soekanto, S. (1993). Beberapa teori sosiologi tentang struktur masyarakat. Jakarta: Raja Grafindo Persada.

Steinberg, L. (1993). Adolescence, New York: McGraw-Hill.

Sue, D. W. \& Sue, D. (2008). Counseling the culturally diverse: Theory and practice, $5^{\text {th }}$ ed. New Jersey: John Wiley \& Sons, Inc.

Suherman, U. (2013). Bimbingan dan konseling karir: sepanjang rentang kehidupan: Bandung: Rizki.

Surya, M. (2003). Peluang dan tantangan global bagi profesi bimbingan dan konseling: Implikasinya bagi strategi organisasi dan standarisasi bimbingan dan konseling. Makalah Konvensi Nasional XIII Bimbingan dan Konseling: Profesi bimbingan dan konseling Indonesia menuju ke arah standar internasional. Bandung: Kerjasama ABKIN dengan Universitas Pendidikan Indonesia.

Tilaar, H. A. R. (1999). Pendidikan, kebudayaan \& masyarakat madani Indonesia. Bandung: Remaja Rosda Karya.

UNESCO PROAP. (1998). Learning to live together in peace and harmony; Vaules education for peac, human rights, democraty, and sustainable development for Asia-Pacific Region: a UNESCO-APENIVE Sourcebook for Teacher Education and Tertiary Level Education. Bangkok: UNESCO.

Waterman, A. S. (1988). Identity status theory and Erikson's theory: Communalities and differences. Developmental Review, 8(2), 185-208

Yost, D. S., Sentner, S. M., \& Forlenza-Bailey, A. (2000). An examination of the construct of critical reflection: Implications for teacher education programming in the 21 st century. Journal of teacher education, 51(1), 3949. 